\title{
DESENVOLVIMENTO DE PERIFÍTON EM TANQUES EXPERIMENTAIS, SUBMETIDOS A DIFERENTES ADUBAÇÕES ORGÂNICAS
}

\section{Rita de Cassia Rodrigues ${ }^{1}$}

Carmino Hayashi ${ }^{2}$

RESUMO: Com o objetivo de avaliar os efeitos de diferentes adubações orgânicas sobre o desenvolvimento do perifíton, foram utilizados, estrumes de aves (EA), bovinos (EB), coelhos (EC) e suínos (ES), em um delineamento inteiramente casualizado com quatro tratamentos e quatro repetições, em tanques de 1000L. Foram realizadas adubações semanais na proporção de 2,5 $\mathrm{g} /$ tanque, sendo a dose inicial de $20 \mathrm{~g} /$ tanque e juntamente com a primeira adubação foi inoculado "plâncton selvagem". Em cada tanque foram estocadas 500 larvas de piavuçu (L. macrocephalus), sendo também colocadas três baterias com 12 lâminas de vidro (2,50 x 7,50 cm de largura e altura, respectivamente), em suporte de madeira, posicionados em três profundidades $(10,00 ; 25,00$ e 40,00 cm). A cada três dias foram realizadas as coletas do perifíton, assim como foram monitoradas as variáveis físicas e químicas. A densidade média máxima do perifíton total foi encontrada nos tanques adubado com EA, atingindo $2107835 \times 10^{4} \mathrm{org} . / \mathrm{cm}^{2}$, seguido de ES com $1951277 \times 10^{4} \mathrm{org} . / \mathrm{cm}^{2}$, EC com $1721231 \times 10^{4} \mathrm{org} . / \mathrm{cm}^{2}$ e por fim, EB com $120.0696 \times 10^{4}$ org. $/ \mathrm{cm}^{2}$. Constatou-se que entre os fertilizantes usados, o que apresentou melhores resultados em termos de produção perifítica foi o de EA, seguido por ES, EC e EB, havendo predominância do gênero Nitzschia em todos os tratamentos. Conclui-se que os diferentes tratamentos levaram à diferenças na densidade da comunidade perifítica, e que EA promove maior produção de perifíton na superfície em relação aos demais tratamentos.

Palavras-chave: Adubação orgânica. Larvicultura. Organismos alimento. Perifíton.

\footnotetext{
${ }^{1}$ Programa de Pós-Graduação em Ecologia de Ambientes Aquáticos Continentais, UEM -Universidade Estadual de Maringá, Maringá/PR

${ }^{2}$ PVNS/CAPES/UFTM - Universidade Federal do Triângulo Mineiro - Uberaba/MG Autor para correspondência: e-mail: hayashi@terra.com.br
} 


\section{INTRODUÇÃO}

O termo perifíton foi definido por Sladeckavá (1962) como comunidade de organismos que vivem aderidos ou associados a diferentes substratos aquáticos; ou especificamente, são organismos que apresentam estruturas especiais para fixação e, de pseudoperifíton, aqueles que apresentam vida livre e não estão claramente associados ao substrato. Ocorrem juntos em todos os substratos, formando uma comunidade única e devem ser analisados com os mesmos métodos (LOBO et al, 1985). Pode atingir alguns milímetros de espessura, atuando na interface entre o substrato e a água circundante, como um microcosmo onde ocorrem processos internos autotróficos e heterotróficos e processos de trocas com o meio externo. A ampla ocorrência de camadas microbianas em superfícies submersas constitui um indicativo de que microrganismos perifíticos possuem importante papel em ecossistemas aquáticos, pois eles desenvolvem-se em resposta à concentração de nutrientes nas superfícies e têm importância ecológica, influenciando a distribuição de plantas e animais (ZOBELL; FELTHAM, 1942).

A produção de organismos alimentos para larvas de peixes na fase inicial é fundamental, devido ao reduzido tamanho de sua boca e impossibilidade de ingerir rações (FERMIN; SERONAY, 1997; PEGANO et al., 1999; FARIA et al., 2000). No Brasil foram feitos alguns estudos sobre a produção de plâncton, visando a solução de problemas relacionados à alimentação larval, destacando-se os trabalhos de Furuya et al. (1999), Soares et al. (2000) e Santeiro; Pinto-Coelho (2001). O uso de zooplâncton tem proporcionado bons resultados na larvicultura do pacu, proporcionando um melhor desempenho das pós-larvas quanto ao tamanho, sobrevivência e resistência aos estresses (PRIETO et al, 2006).

Resultados encontrados por Faria et al. (2000), constataram que o adubo que levou à melhor produção de zooplâncton foi o de aves, seguidos de suínos e por fim bovinos e coelhos, ao passo que Feiden (1999) estudou a relação entre organismos planctônicos e sua influência sobre o desenvolvimento inicial de piracanjuba em tanques com diferentes adubações orgânicas. As condições ideais dos parâmetros limnológicos para larvicultura, assim como a presença de organismos alimentos são fundamentais para 
um bom desenvolvimento na fase inicial , conforme Feiden et al. (2006).

O perifíton é um recurso alimentar utilizado pelos peixes em fase inicial de desenvolvimento como o piavuçu, Leporinus macrocephalus (HAYASHI et al. 1999) e curimba (Prochilodus lineatus); entretanto necessitam de mais estudos. Entre os estudos de perifítons empregados no cultivo de peixes, citamos o de Wahab et al. (1999), apontando que o perifíton contribui para um melhor crescimento e desenvolvimento de larvas de peixes. Sartori et al. utilizou manejos de adubação em cultivo de arroz irrigado, obtendo paralelamente o desenvolvimento de microalgas (fitoplâncton e perifíton); tal como Huchette et al. (2000), estudaram o desenvolvimento da comunidade perifítica associada ao cultivo de tilápias em tanques artificiais.

Considerando-se a importância dos organismos alimentos na larvicultura, tornam-se imprescindíveis pesquisas que promovam melhorias nas metodologias de cultivos. Esta assertiva pode ser confirmada por Lombardi; Gomes (2008), que asseguram não ser recomendável substituir o alimento vivo por alimento inerte em larvicultura de tambacu.

Este trabalho teve como objetivo estudar o desenvolvimento da comunidade perifítica em seus aspectos qualiquantitativos, relacionando os diferentes grupos taxonômicos em função de diferentes adubações orgânicas e profundidades em tanques experimentais.

\section{MATERIAIS E MÉTODOS}

O experimento foi conduzido em 16 tanques de fibrocimento (1000L), que foram previamente preparados, recebendo aeração contínua, adubação e inoculação com "plâncton selvagem". Cada tanque recebeu 500 larvas de piavuçu (72 horas pós-eclosão), com comprimento inicial médio de 4,66 $\pm 0,29 \mathrm{~mm}$. O delineamento experimental foi inteiramente casualizado com quatro tratamentos e quatro repetições, sendo: esterco de aves (EA), bovinos (EB), coelhos (EC), suínos (ES).

Amostras dos estercos utilizados foram secas em estufa de ventilação forçada por 48 horas e acondicionada para análises de Digestão Sulfúrica (com catalizadores): N, determinados através de semimicro-Kjedahl, sendo os valores do nitrogênio obtido através 
de análise foliar segundo a metodologia de Malavolta et al. (1997). Já os valores dos demais macronutrientes foram obtidos através de análise de solos, segundo a Comissão Estadual de Laboratórios de Análises Agronômicas do Estado do Paraná (Silva, 1999). Os estercos foram aplicados num total de 32,50 gramas em cada tanque ao longo do experimento.

Para coleta do perifíton, cada tanque recebeu três suportes de madeira com 12 lâminas de vidro $(2,50 \times 7,50 \mathrm{~cm})$, sendo estas baterias fixadas na superfície, no meio e no fundo do tanque; correspondendo a profundidades de 10,0; 25,0 e 40,0 cm, respectivamente. As identificações dos organismos foram feitas de acordo com Bicudo; Bicudo (1970), Bicudo (1990a), Bicudo (1990b) e Barrientos; Bicudo (1995).

A temperatura da água e do ar foram medidas duas vezes ao dia (8h00 e 16h00), assim como foram tomadas medidas de $\mathrm{pH}$, oxigênio dissolvido e condutividade elétrica a cada três dias, quando foi coletada uma lâmina de cada profundidade. O perifíton aderido em uma área de 2,50 x 6,00 cm (largura e altura) nas lâminas foram coletadas e fixadas em solução de lugol acético para serem analisadas posteriormente.

Ao final do período experimental foram contadas e pesadas todas as larvas de cada tanque e para análises estatísticas dos dados de biomassa, peso final médio e taxa de sobrevivência dos peixes realizou-se análise de variância a 5\% de probabilidade e em caso de diferenças foi utilizado o teste de média de Tukey a 5\%, pelo programa computacional SAEG (2007).

\section{RESULTADOS E DISCUSSÃO}

Os valores dos macronutrientes dos estercos utilizados para adubação dos tanques estão na Tabela 1. Observa-se que o maior teor de nitrogênio ocorre em EA, seguido por ES, sendo que EB e EC apresentam valores inferiores. Em relação aos teores de fósforo, EA apresenta valores mais elevados seguido por ES, EC e EB. Ressalta-se ainda que EA apresentam altos valores de potássio que os demais estercos. 
Tabela 1- Valores dos macronutrientes dos estercos utilizados no experimento ${ }^{1}$

\begin{tabular}{|c|c|c|c|c|c|}
\hline & \multicolumn{4}{|c|}{ Estercos } \\
\hline & & Aves & Bovinos & Coelhos & Suínos \\
\hline \multirow[t]{2}{*}{$\mathrm{PH}$} & $\mathrm{CaCl}_{2}$ & 8,00 & 7,20 & 7,20 & 7,40 \\
\hline & $\mathrm{H}_{2} \mathrm{O}$ & 8,20 & 7,70 & 7,80 & 7,70 \\
\hline & 1,74 & 2,03 & 1,88 & 1,74 \\
\hline & & 8,68 & 8,66 & 8,83 & 12,17 \\
\hline \multicolumn{2}{|c|}{$\begin{array}{l}\mathrm{Ca}^{++}+\mathrm{Mg}^{++}\left(\mathrm{cmol}_{\mathrm{e}} \mathrm{dm}^{-3}\right) \\
\mathrm{Ca}^{++}\left(\mathrm{cmol}_{\mathrm{e}} \mathrm{dm}^{-3}\right)\end{array}$} & 2,93 & 3,23 & 3,71 & 4,61 \\
\hline \multicolumn{2}{|c|}{$\mathrm{K}^{+}\left(\mathrm{cmol}_{\mathrm{e}} \mathrm{dm}^{-3}\right)$} & 33,39 & 2,18 & 5,13 & 4,33 \\
\hline \multicolumn{2}{|c|}{$\mathrm{P}\left(\mathrm{mg} \mathrm{dm}^{-3}\right)$} & 6082 & 943 & 1032 & 5305 \\
\hline \multicolumn{2}{|l|}{$\mathrm{C}\left(\mathrm{g} \mathrm{dm}^{-3}\right)$} & 342,45 & 364,22 & 525,91 & 491,26 \\
\hline \multicolumn{2}{|l|}{$\mathrm{N}\left(\mathrm{g} \mathrm{kg}^{-1}\right)^{*}$} & 32,0 & 19,0 & 18,0 & 31,0 \\
\hline
\end{tabular}

'Digestão Sulfúrica (com catalizadores): N: Laboratório de Análises de Solos e Tecido Vegetal do DAG/UEM

Os valores médios da densidade total dos organismos perifíticos em tanques submetidos a diferentes adubações orgânicas encontram-se na Tabela 2. A densidade média máxima do perifíton total foi encontrada nos tanques adubados com $E A$, atingindo $2107835 \times 10^{4} \mathrm{org} . / \mathrm{cm}^{2}$, seguido de ES com $1951277 \times 10^{4} \mathrm{org} . / \mathrm{cm}^{2}$, EC com $1721231 \times$ $10^{4}$ org. $/ \mathrm{cm}^{2}$ e por fim, EB com $120.0696 \times 10^{4}$ org. $/ \mathrm{cm}^{2}$ (Figura 1).

De acordo com Siqueira (2008), para que o perifíton atinja o estágio de maturidade seriam necessários acima de 21 dias, o que ocorreu no presente trabalho. Estudos de Oliveira; Schwarzbold (1998), demonstrou que até o 22ํ dia, predominaram Bacillariophyceae, porém, ao $100^{\circ}$ dia, Chlorophyceae foi melhor representada; substituição esta que decorre do crescimento predominante e às variações na localização da comunidade perifítica no processo de amadurecimento, uma vez que Bacillariophyceae crescem prostradas verticalmente aderidas, e as algas verdes estabelecem-se nos estratos superiores da comunidade.

Tabela 2- Valores médios das densidades totais dos organismos $\left(1 \times 10^{4}\right)$ perifíticos nos tanques $^{1}$

\begin{tabular}{|c|c|c|c|c|c|c|c|c|c|c|c|c|c|}
\hline & \multicolumn{12}{|c|}{ Tempo (dias) } & \multirow[b]{2}{*}{ média } \\
\hline & 3 & 6 & 9 & 12 & 15 & 18 & 21 & 24 & 27 & 30 & 33 & 36 & \\
\hline \multirow[t]{2}{*}{ Aves } & 0,1 & 33,00 & 64,2 & 142,4 & 76,7 & 146,4 & 165,5 & 281,7 & 211,8 & 257,4 & 292,9 & 567,8 & 210,7 \\
\hline & & & & & & & & & & $\mathrm{a}$ & & $\mathrm{a}$ & $\mathrm{a}$ \\
\hline \multirow[t]{2}{*}{ Bovinos } & 0,25 & 23,6 & 51,9 & 70,0 & 93,4 & 96,2 & 133,5 & 110,7 & 83,2 & 170,0 & 272,0 & 245,2 & 120,1 \\
\hline & & & & & & & & & & $\mathrm{b}$ & & $\mathrm{b}$ & $\mathrm{b}$ \\
\hline \multirow[t]{2}{*}{ Coelhos } & 0,2 & 21,4 & 47,7 & 48,1 & 41,18 & 46,9 & 132,0 & 136,2 & 205,0 & 257,8 & 313,3 & 442,7 & 172,1 \\
\hline & & & & & & & & & & $\mathrm{a}$ & & $\mathrm{ab}$ & $\mathrm{ab}$ \\
\hline \multirow[t]{2}{*}{ Suínos } & 0,3 & 19,2 & 85,72 & 135,1 & 104,0 & 125,7 & 231,1 & 216,6 & 192,3 & 255,0 & 349,2 & 410,2 & 195,1 \\
\hline & & & & & & & & & & $\mathrm{ab}$ & & $\mathrm{ab}$ & $\mathrm{a}$ \\
\hline
\end{tabular}


No $27^{\circ}$ dia, os tratamentos EA e EC levaram a maiores densidades $(p<0,05)$ em relação à do tratamento $E B$, no entanto não diferiram $(p>0,05)$ dos valores do tratamento ES. No $36^{\circ}$ dia, o tratamento EA levou à densidades mais elevadas $(p<0,05)$ em relação ao tratamento $E B$, não diferindo $(p>0,05)$ entretanto dos valores obtidos em EC e ES. Estes resultados são similares aos obtidos por Feiden (1999) e Faria et al. (2000) que encontraram maiores densidades de zooplâncton quando utilizaram esterco de aves. Não foram observadas diferenças significativas $(p>0,05)$ entre os valores médios de densidade total dos organismos perifíticos entre os tratamentos em função do posicionamento das lâminas em diferentes níveis.

O tratamento EA levou aos maiores valores de densidade de organismos na superfície, enquanto que nas profundidades meio e fundo os tratamentos EA, EC e ES apresentaram valores similares ao longo do experimento. Os tratamentos EA, EC e ES apresentaram maiores densidades no $36^{\circ}$ dia e EB no $33^{\circ}$ dia. Observou-se a predominância do gênero Nitzschia em todos os tratamentos (Figura 2), com maiores densidades na superfície e meio com o uso de EA e menores para EB e EC. Este gênero atingiu no 36을 dia, valores máximos de produção total de 6202880, 2516480, 2481600 e $1938688 \mathrm{org} / \mathrm{cm}^{2}$ para os tratamentos EA, ES, EC e EB, na superfície, meio e superfície, respectivamente.

Em relação aos valores de densidade dos diferentes gêneros e grupos nos tanques ao longo do período experimental (Figuras 3, 4, 5 e 6), no $33^{\circ}$ dia notou-se que os tratamentos EA e ES, mostraram altas densidades de organismos, com poucos gêneros, características de ambiente eutrofizado (ESTEVES, 2011). Esses resultados assemelhamse aos encontrados por Reis (1986) que estudou produção de plâncton com esterco de aves e bovinos, observando maior produção em tanques adubados com esterco de aves. Observa-se ainda que além de Nitzschia, os organismos mais representativos foram Scenedesmus, seguido por Clorella, Gomphonema, Desmidium, Dictyosphaerium, Eunotia e Navicula.

Valores maiores de densidades encontrados em EA e ES, provavelmente se devem ao fato destes apresentarem maiores teores de $\mathrm{N}$ e P, conforme Tabela 1, pois o aumento destes nutrientes elevam a produção primária (SIPAÚBA-TAVARES, 1994). Embora o gênero Nitzschia tenha predominado em todos os tratamentos, até a última 
coleta não atingiu valores máximos de densidades (Figura 2).

Observa-se que Scenedesmus foi mais representativos em todos os tratamentos nos três níveis, atingindo no 36ำ dia em tanques EA-fundo, valores máximos de 393280 org $/ \mathrm{cm}^{2}$. Já em tanques EB, no $12^{\circ}$ dia, atingiu valor de $278080 \mathrm{org} / \mathrm{cm}^{2}$ na superfície, mantendo-se em densidades elevadas em todos os níveis. Em EC, Figura 4, no 36 dia, no fundo, foram encontrados $640960 \mathrm{org} / \mathrm{cm}^{2}$. Com ES, Figura 6, na superfície ocorreu densidade de $561664 \mathrm{org} / \mathrm{cm}^{2}$ no $18^{\circ}$ dia.

Chlorella sp atingiu valores máximos no $36^{\circ}$ dia de $325840 \mathrm{org} / \mathrm{cm}^{2}$ no fundo, de 279680 no meio e de $246080 \mathrm{org} / \mathrm{cm}^{2}$ no fundo com EA, EC e ES, respectivamente, mostrando que poderia ainda atingir maior crescimento. Já em EB, a densidade alcançada no $33^{\circ}$ dia com 228224 org $/ \mathrm{cm}^{2}$ na superfície. O gênero Desmidium atingiu valores máximos de 327680 org $/ \mathrm{cm}^{2}$ no fundo, nos tanques com EA no $36^{\circ}$ dia e 171904 org/cm ${ }^{2}$, na superfície, nos tanques com ES no $30^{\circ}$ dia (Figuras 3 e 6), e valores de 167232 org/cm² na superfície e 628608 org $/ \mathrm{cm}^{2}$ no meio, nos tanques com EB e EC no 33ํ dia (figuras 4 e 5), diminuindo a densidade.

Em tanques EA, Dictyosphaerium atingiu valor de $219840 \mathrm{org} / \mathrm{cm}^{2}$ no fundo, no $36^{\circ}$ dia, e de 394240 org $/ \mathrm{cm}^{2}$ na superfície com EC no $36^{\circ}$ dia, tendo valores elevados em todos os níveis nesta mesma data. Com EB ocorreu densidade máxima de 84928 org/cm² no $33^{\circ}$ dia na superfície, e nesta mesma data em ES apresentou o valor de 400256 $\mathrm{org} / \mathrm{cm}^{2}$ na superfície.

As maiores densidade de Eunotia nos tanques com EA foi de 295488 org $/ \mathrm{cm}^{2}$ na superfície, no $12^{\circ}$ dia, apresentando altos valores em todas as profundidades no $21^{\circ}$ dia. Com EB o maior valor desta alga foi encontrado no fundo com $160384 \mathrm{org} / \mathrm{cm}^{2}$ no $15^{\circ} \mathrm{dia}$. Em todos os níveis houve densidade máxima com EC no $36^{\circ}$ dia, onde a maior densidade foi de 203200 org/ $\mathrm{cm}^{2}$ na superfície. Já com ES, a maior densidade de Eunotia, foi no meio com 261248 no $12^{\circ}$.

Em relação ao gênero Gomphonema as maiores densidades ocorreram com EA no $12^{\circ}$ dia, com 295488 org $/ \mathrm{cm}^{2}$ na superfície e de $237120 \mathrm{org} / \mathrm{cm}^{2}$, com EB no $15^{\circ}$ dia no fundo. Com EC apresentou densidade de $246400 \mathrm{org} / \mathrm{cm}^{2}$ na superfície no $36^{\circ}$ dia e com ES, valor de $346944 \mathrm{org} / \mathrm{cm}^{2}$ na superfície no $18^{\circ}$ dia. Navicula, teve densidades de

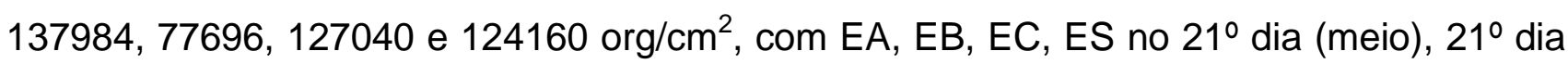




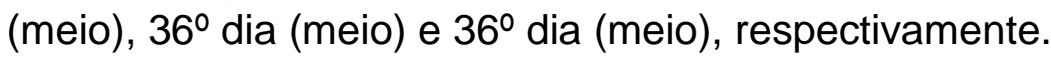

Houve diferenças nas densidades e na produção máxima apresentados pelos diferentes gêneros e em relação a profundidade, o que é explicado por Lobo et al. (1985) e Fulone (2012), que o estabelecimento da comunidade perifítica em um substrato artificial, deve ser explicado conforme uma sucessão ecológica, porém, considerando que as características estruturais dessa comunidade atingem valores máximos de acordo com as diferenças na distribuição espaço-temporal das espécies, condições do meio, estações do ano e das características adaptativas das mesmas.

A dominância e persistência espaço-temporal das diatomáceas refletem possivelmente as condições estáveis do ambiente; o que pode ser verificado através da presença de Nitzschia, Eunotia, Gomphonema e Navicula, que são gêneros colonizadores e mantiveram a dominância todas as coletas. Em todas as profundidades, as diatomáceas destacaram-se, provavelmente pelas suas amplas tolerâncias ecológicas, o que favorece uma adaptação rápida às condições locais (Lobo et al., 1985).

Em relação às diferentes profundidades, ocorreu maior densidade de organismos com EA na superfície, conforme mostra a Figura 1. Quanto à produção do gênero Nitzschia, a maior densidade foi no tratamento EA, na superfície, onde atingiu no 36ํ dia, valores máximos com produção total de 6202880, 2516480, 2481600 e 1938688 org $/ \mathrm{cm}^{2}$, para os tratamentos EA, ES, EC e EB, na superfície, meio e superfície, respectivamente (Figura 2). Este resultado pode estar relacionado aos maiores teores de $\mathrm{N}$ e $\mathrm{P}$ em EA e ES e à maior intensidade luminosa na superfície.

Soares (1981) analisando a comunidade perifítica em substrato natural, identificou maior biomassa na superfície, quando comparada com maiores profundidades. Esta distribuição vertical do fitoplâncton pode ser determinada pela composição química, radiação e temperatura da água. Isto mostra que estes fatores podem influenciar também a distribuição vertical dos organismos perifíticos.

$\mathrm{Na}$ Tabela 3 são apresentados os valores médios das características de desempenho das larvas de piavuçu, nos tanques submetidos às diferentes adubações orgânicas. 
Tabela 3- Valores médios de características de desempenho de larvas de piavuçu, em tanques submetidos a diferentes adubações orgânicas

\begin{tabular}{lllcll}
\hline & \multicolumn{5}{c}{ Tratamentos (estercos) } \\
\cline { 2 - 6 } & Aves & Bovinos & Coelhos & Suínos & CV $(\%)$ \\
\hline Biomassa $(\mathrm{g})$ & $14,80^{\mathrm{a}}$ & $10,33^{\mathrm{ab}}$ & $6,95^{\mathrm{b}}$ & $11,65^{\mathrm{ab}}$ & 23,91 \\
Peso final médio (mg) & 82,90 & 69,80 & 52,80 & 70,10 & 32,08 \\
Taxa de sobrevivência $(\%)$ & 39,63 & 33,67 & 28,67 & 35,90 & 21,82 \\
\hline \multicolumn{2}{l}{ Valores seguidos de mesma letra não diferem estatisticamente pelo Teste de Tukey (p>0,05) }
\end{tabular}

Valores seguidos de mesma letra não diferem estatisticamente pelo Teste de Tukey $(p>0,05)$

A biomassa final dos alevinos onde foi utilizado EA foram superiores $(p<0,05)$ em relação aos dos tanques com EC, não diferindo ( $p>0,05)$ dos valores obtidos com EB e ES. Não foram observadas diferenças $(p>0,05)$ entre a utilização dos diferentes estercos sobre o peso final e taxa de sobrevivência.

Os valores médios do $\mathrm{pH}$ da água nos quatro tratamentos mantiveram-se entre 7,0 e 8,7; valores estes considerados adequados para a maioria dos organismos aquáticos (MITCHEEL; JOUBERT, 1986). Observou-se que no 9 dia $0 \mathrm{pH}$ atingiu valores mais elevados, com valores de 8,41, 8,52, 8,36 e 8,67; em EA, EB, EC e ES, respectivamente. Para a condutividade elétrica, os tratamentos apresentaram valores maiores no $36^{\circ}$ dia, com valores de 259,5; 256,5; 248,25 e 241 com EC, EB, EA e ES respectivamente. Em relação ao oxigênio dissolvido, houve um aumento gradual no decorrer do experimento, atingindo maiores valores no 33ำ dia, com 14,0;13,8; 13,4 e 12,9 em EC, EB, EA e ES, respectivamente. A temperatura da água oscilou entre $21,0-26,0^{\circ} \mathrm{C}$ (manhã) e 22,0-29,0ㄷ (tarde), com maiores valores à tarde entre o 21-23 dia. Considerando-se estes resultados para os fatores abióticos, podemos considerá-los dentro dos valores recomendados para aquicultura, segundo Egna; Boyd (1997).

\section{CONCLUSÕES}

Os resultados indicam que os diferentes tratamentos utilizados levaram às diferenças na comunidade perifítica, sendo que a adubação com melhor resultado na produção do perifíton foram os de aves, seguido de suínos, coelhos e bovinos. Houve predominância do gênero Nitzschia em todos os tratamentos, além deste, os organismos mais representativos foram Scenedesmus, Chlorella, Gomphonema, Desmidium, 
Dictyosphaerium, Eunotia e Navicula. Portanto, a adubação EA deve ser a mais indicada para a produção perifitica, de modo a incrementar organismos alimentos para algumas espécies de peixes em suas fases iniciais de desenvolvimento.

\section{REFERÊNCIAS}

BARRIENTOS, O.O.P.; BICUDO, C.E.M. Introducción a la biología y sistemática de las algas de aguas continentales. Santiago, Chile: Universidade de Concepcion, 1995.

BICUDO, C.E.M. Metodologia para o estudo qualitativo das algas do perifíton. Acta limnologica Brasiliense, Botucatu, v. 3, p.477-491, 1990b.

BICUDO, C.E.M.; BICUDO, R.M.T. Algas de águas continentais brasileiras. São Paulo, Fundação Brasileira para o Desenvolvimento de Ensino de Ciências, 1970. 228 p.

BICUDO, D.C. Considerações sobre metodologias de contagem de algas do perifíton. Acta limnologica Brasiliense, Botucatu, v. 3, p.459-475, 1990a.

EGNA, H.S.; BOYD, E.C. Dynamics of pond aquaculture. Boca Raton: CRC Press, 1997. $342 p$.

ESTEVES, F.A. Fundamentos de Limnologia. 3.ed. Rio de Janeiro: Interciência, Finep, 2011. 828p.

FARIA, A.C.E.A. et al. Utilização de diferentes substratos orgânicos em tanques experimentais para a produção de zooplâncton. Acta Scientiarum, Maringá, v. 22, n.2, p.375-381, 2000.

FEIDEN, A. Fitozooplancton produzido por substratos de adubação orgânica associado ao desenvolvimento de juvenis de piracanjuba, Brycon orbignianus Valenciennes, 1849 (Teleostei: Characidae) em tanques experimentais. 1999. (Tese de Doutorado Universidade Estadual de Maringá). Maringá/PR, 1999.

FEIDEN, A. et al. Desenvolvimento de larvas de surubim do Iguaçu (Steindachneridion melanodermatum) submetida a diferentes dietas. Rev. Bras. Zootecnia, Viçosa, v. 35, n. 6, p. 2203-2210, 2006.

FERMIN, A.C.; SERONAY, G.A. Effects of different illumination levels on zooplankton abundance, feeding periodicity, growth and survival of Asian sea bass, Lates calcarifer (Bloch), fry in illuminate floating nursey cages. Aquaculture, Amsterdan, v. 157, n.3, p.227237, 1997. 
FULONE, L.J. Perifíton heterotrófico: colonização e influência do pulso

hidrossedimentológico em uma planície de inundação neotropical. 2012. 48 p. (Tese de Doutorado -Programa de Pós-Graduação em Ecologia de Ambientes Aquáticos Continentais. Universidade Estadual de Maringa. 2012.

FURUYA, V.R.B. et al. Influência de plâncton, dieta artificial e sua combinação sobre o crescimento e sobrevivência de larvas de curimbatá (Prochilodus lineatus). Acta Scientiarum, Maringá, v. 21, n.3, p.699-703, 1999.

HAYASHI, C. et al. Produção fito-zooplanctônica e alimentação natural de larvas de piavuçu (Leporinus macrocephalus, L.) em tanques experimentais. In: ENCONTRO BRASILEIRO DE ICTIOLOGIA, 3, 1999, São Carlos. Resumos... São Carlos, UFSCar/SBI, p. 530.

HUCHETTE, S.M.H. et al. The impacts of grazing by tilapias (Oreochromis niloticus L.) on periphyton communities growing on artificial substrate in cages. Aquaculture, Bangladesh, v. 186, p.45-60, 2000.

LOBO, E.; BUSELATO-TONIOLLI, T.C. Tempo de exposição de um substrato artificial para o estabelecimento da comunidade de perifíton no curso inferior do Rio Caí, Rio Grande do Sul, Brasil. Rickia, São Paulo, v. 12, p.35-51, 1985.

LOMBARDI, D. C. \& GOMES, L. C. Substituição de alimento vivo por alimento inerte na larvicultura intensiva do tambacu ( 9 Colossoma macropomum X $\delta$ Piaractus mesopotamicus). Acta Scientiarum. Anim. Sci. Maringá, v. 30, n. 4, p. 467-472, 2008

MALAVOLTA, E., et al. Avaliação do estado nutricional das plantas: princípios e aplicações. 2. ed. Piracicaba - São Paulo. Potafoz, 1997. 319p.

MITCHEEL, S.A.; JOUBERT, J.H.B. The effect of elevated $\mathrm{pH}$ on the survival and reproduction of Brachionus calyciflorus. Aquaculture, Amsterdan, v. 55, p.215-220, 1986.

OLIVEIRA, M.A.; SCHWARZBOLD, A. Influência de fatores abióticos sobre a estrutura da comunidade perifítica de limnotopos da Bacia do Arroio Sampaio, Mato Leitão, Rio Grande do Sul, Brasil. Porto Alegre. Iheringia Série Botânica, v.51, p.39-61, 1998.

PANITZ, C.M.N. Estudo comparativo do perifíton em diferentes substratos artificiais na Represa do Lobo ("Broa”). São Carlos, 1980. (Dissertação de Mestrado - Universidade Federal de São Carlos). São Carlos, 1980.

PEGANO, M. et al. Zooplankton food and grazing impact in a eutrophic brackish-water tropical pond (Côte d'Ivoire, West Africa). Hydrobiologia, Dordrecht, v. 390, n.1, p.83-98, 1999.

PRIETO, M.J. et al, Tipo de alimento, sobrevivência e desempenho inicial de pós-larvas de pacu (Piaractus mesopotamicus). Ciênc. Agrotec., Lavras, v. 30, n. 5, p. 1002-1007, 2006 
SAEG: sistema para análises estatísticas, versão 9.1. Viçosa: UFV, 2007.

SANTEIRO, R.M.\& PINTO-COELHO, R.M. Efeitos de fertilização na biomassa e qualidade e qualidade nutricional do zooplâncton utilizado para a alimentação de alevinos na estação de hidrologia e piscicultura de Furnas, MG. Acta Scentiarum, Maringá, v. 22,n.2, p.383-388, 2000.

SARTORI, G.M.S. et al. Manejo da adubação e seus efeitos na ocorrência de algas e na produtividade de arroz irrigado em áreas com residual de imidazolinonas. Ciência Rural, Santa Maria, RS, v.41, n.8, ago, p. 1323-1330, 2011.

SILVA, F.C. Manual de Análises Químicas de Solos, Plantas e Fertilizantes. Brasília. Embrapa Informática Agropecuária, 1999.

SIQUEIRA, N.S. Comunidade de algas perifíticas em tanques de cultivo de peixes em reservatório: o processo de colonização e sucessão utilizando substrato artificial. 2008. 57p. (Dissertação de Mestrado - Universidade Estadual de Maringá - UEM), Maringá/PR. 2008.

SLADECKAVA, A. Limnological investigation methods for the periphyton ("Aufwuchs") community. Botanical Review, USA, v. 28, n.2, p.286-350, 1962.

SOARES, C.M. et al. Alimentação natural de larvas de cascudo preto Rhinelepis aspera Agassiz, 1829 (Osteichthyes - Loricariidae) em tanques de cultivo. Boletim do Instituto de Pesca, São Paulo, v. 24 (especial), p.109-117, 1997.

SOARES, C.M. et al. Plâncton, Artemia sp, dieta artificial e suas combinações no desenvolvimento e sobrevivência do quinguio (Carassius auratus) durante a larvicultura. Acta Scientiarum, Maringá, v. 22,n.2. p.383-388, 2000.

SOARES, J.J. Estudos sobre biomassa e produtividade do perifíton em macrófitas na Represa do Lobo. 1981. (Tese (Doutorado - Departamento de Ciências Biológicas). UFSCar. São Carlos/SP 1981.

WAHAB, M.A. et al. The potential of periphyton-based culture of the native major carp calbaush, Labeo calbasu (Hamilton). Aquaculture Research., Bangladesh, v. 30, p.409-419, 1999.

ZOBELL, C. E. \& FELTHAM, C. The bacterial flora of a marine mud flat as an ecological factor. Ecology, Tempe, v. 23, p.69-78, 1942. 

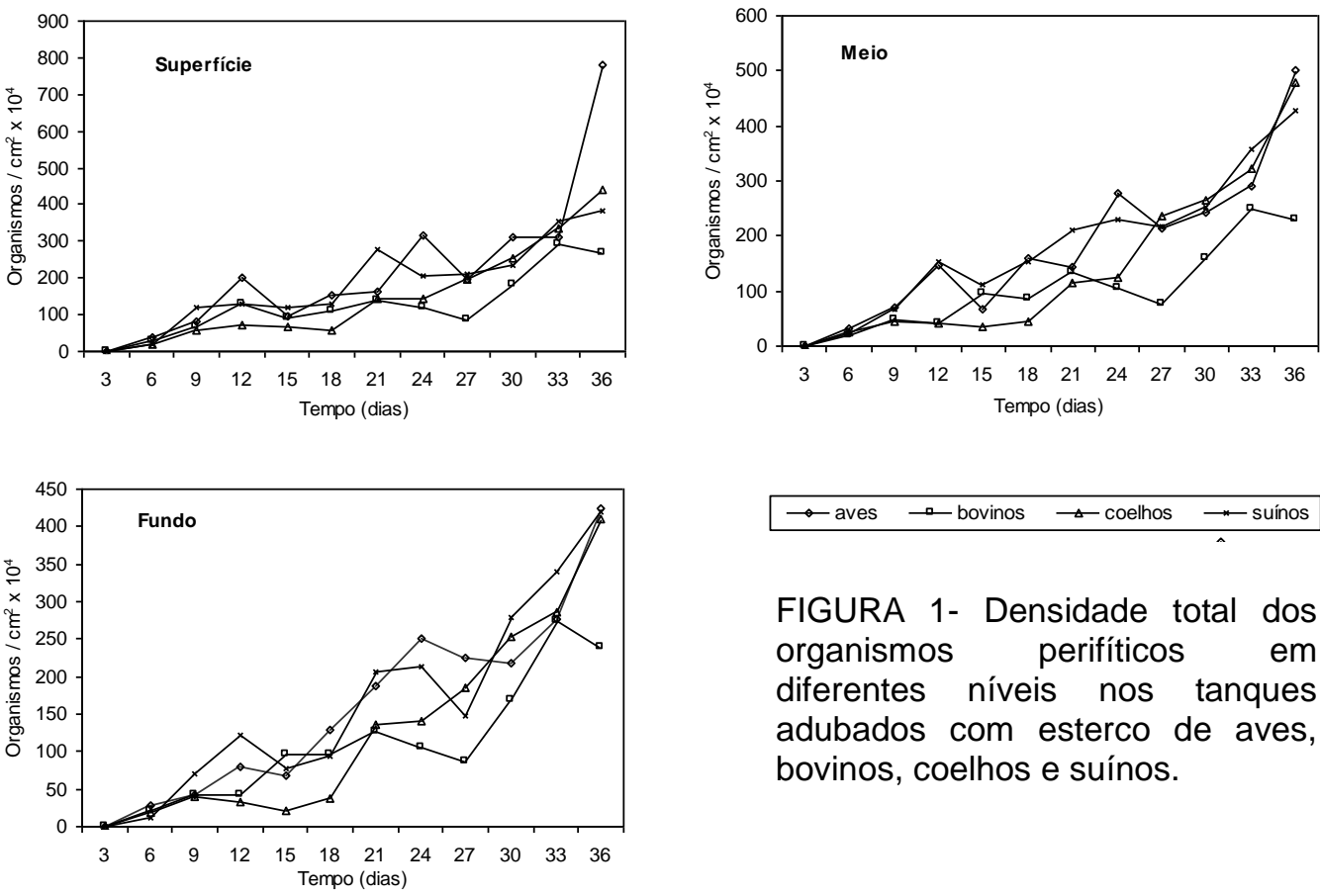

FIGURA 1- Densidade total dos organismos perifíticos em diferentes níveis nos tanques adubados com esterco de aves, bovinos, coelhos e suínos.
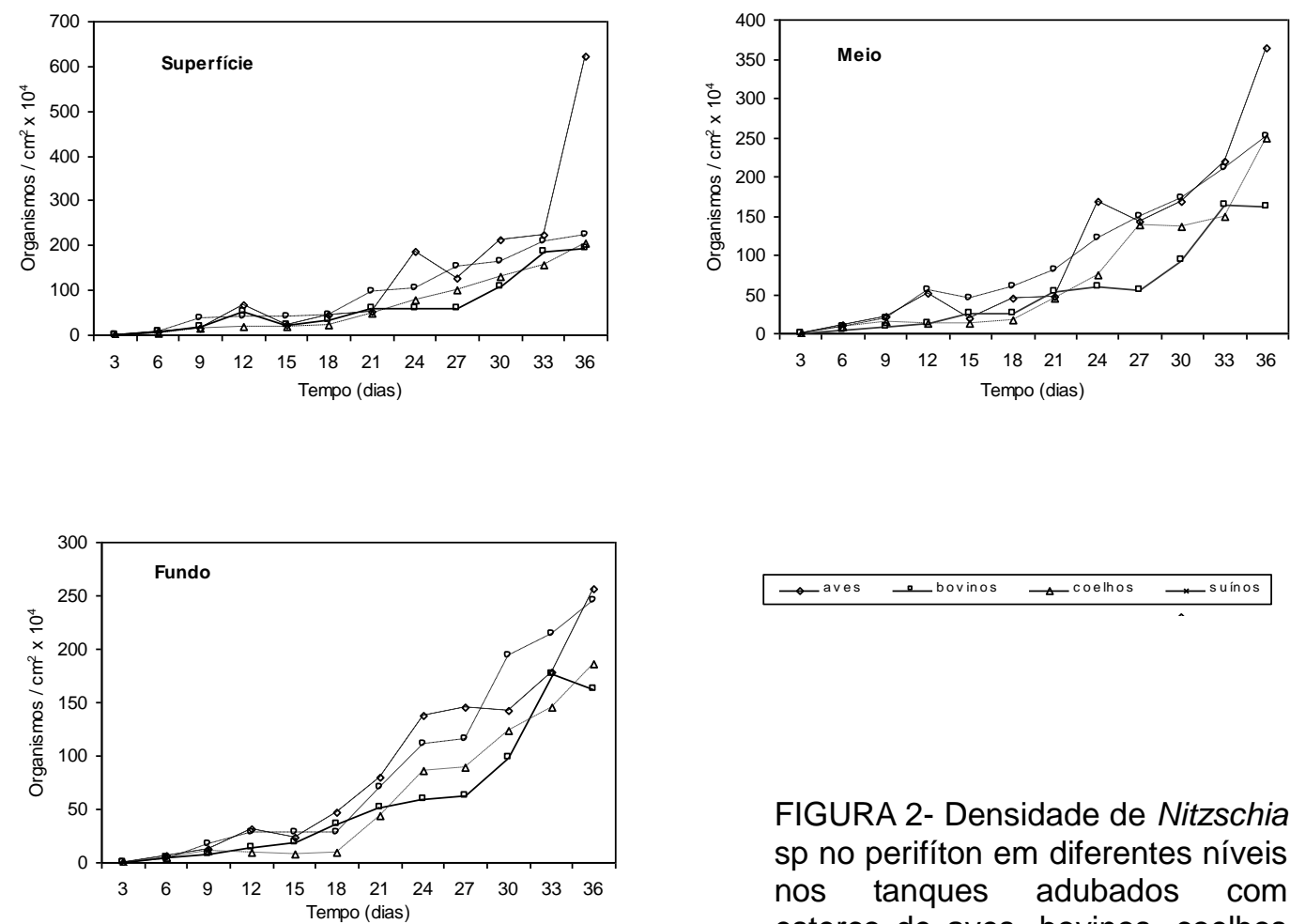

FIGURA 2- Densidade de Nitzschia sp no perifíton em diferentes níveis nos tanques adubados com esterco de aves, bovinos, coelhos e suínos. 

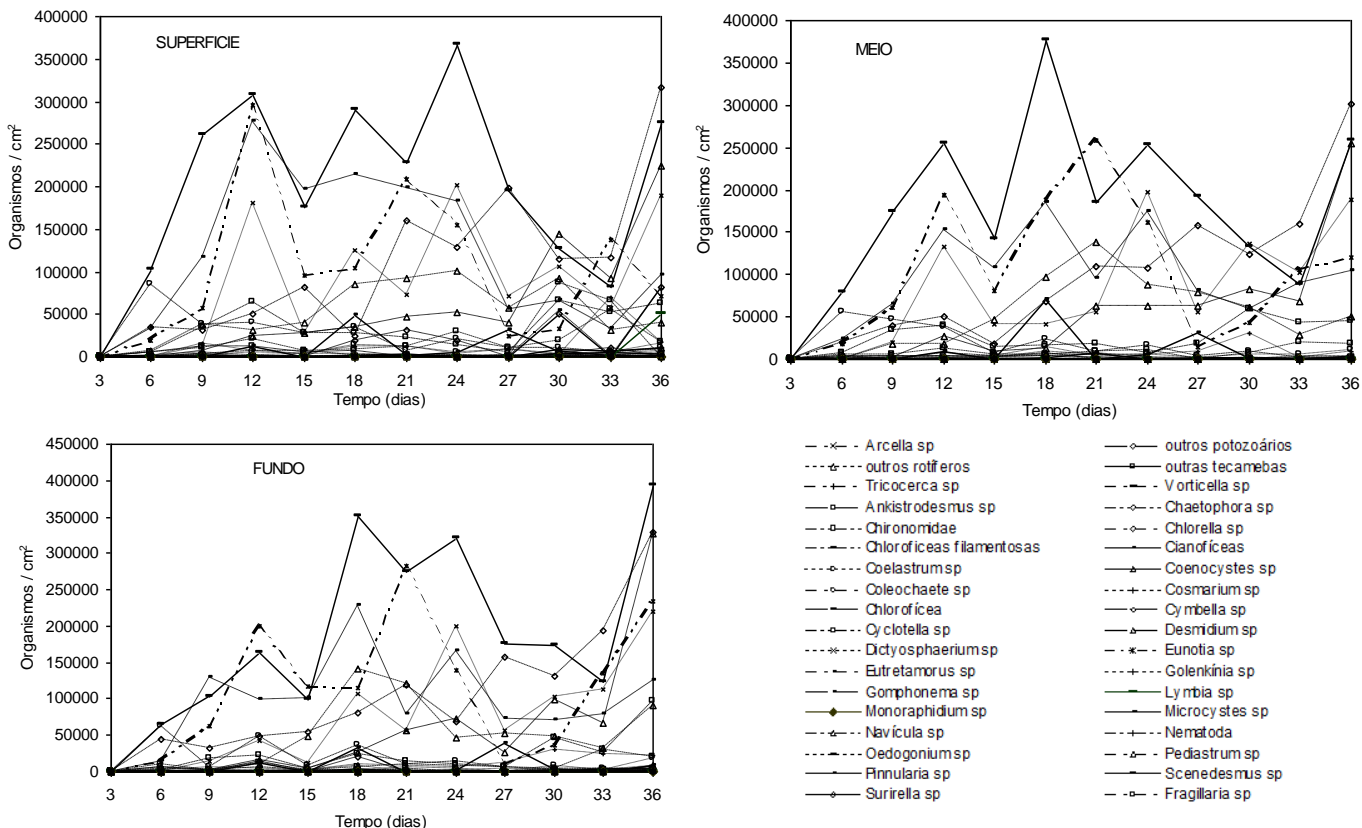

FIGURA 3- Densidade dos organismos perifíticos em diferentes níveis nos tanques adubados com esterco de aves.
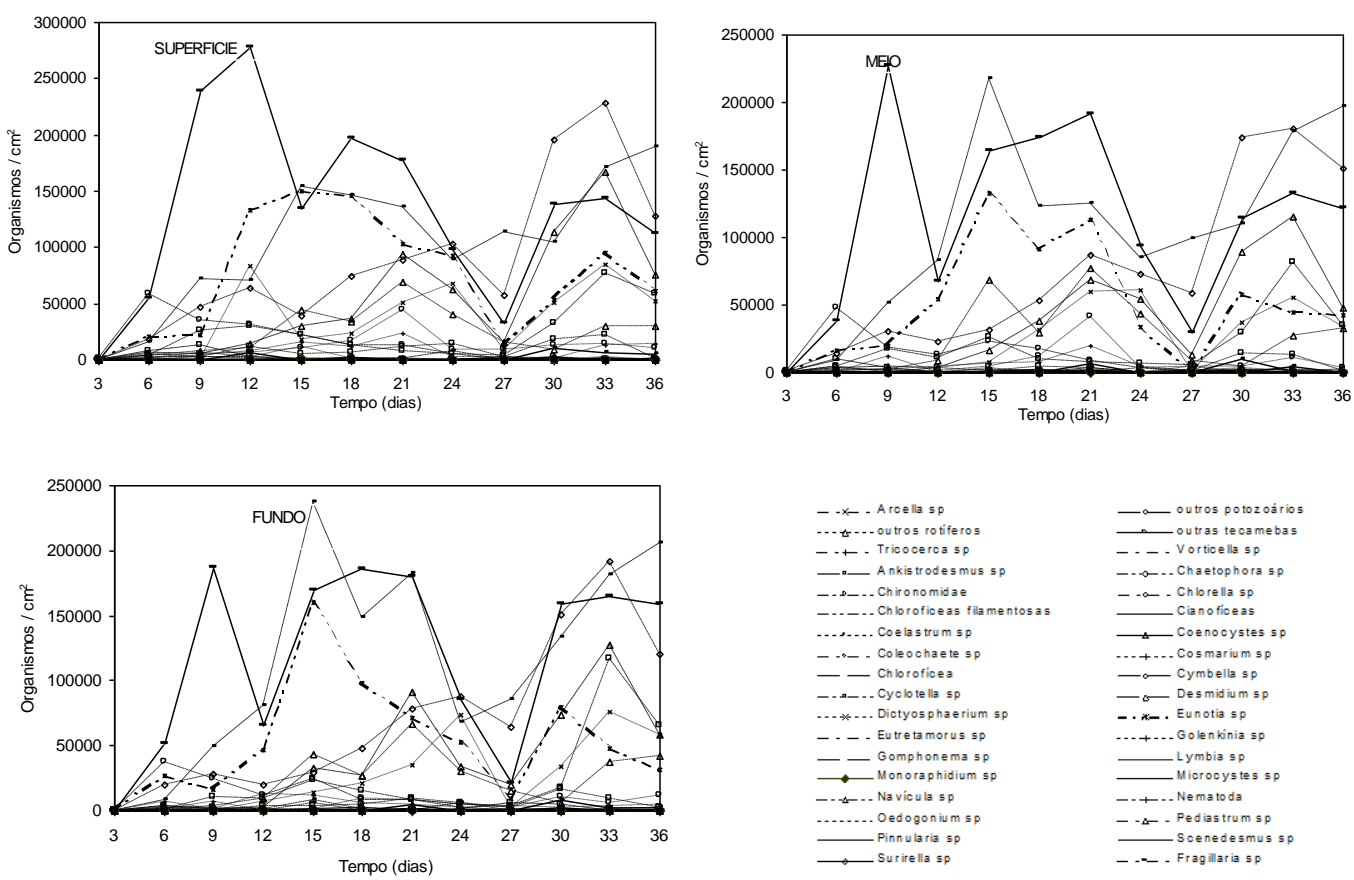

FIGURA 4- Densidade dos organismos perifíticos em diferentes níveis nos tanques adubados com esterco de bovinos. 

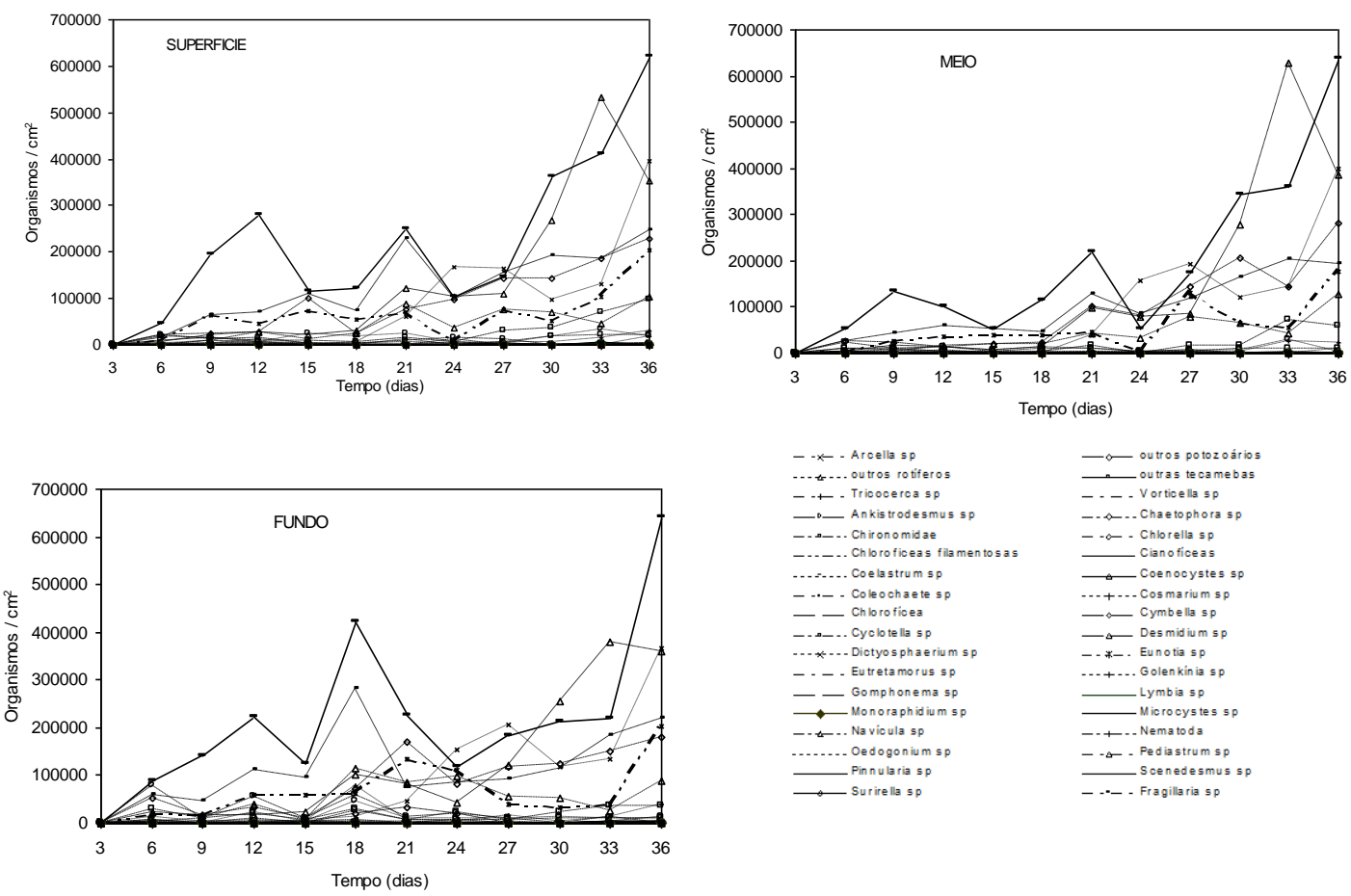

FIGURA 5- Densidade dos organismos perifíticos em diferentes níveis nos tanques adubados com esterco de coelhos.
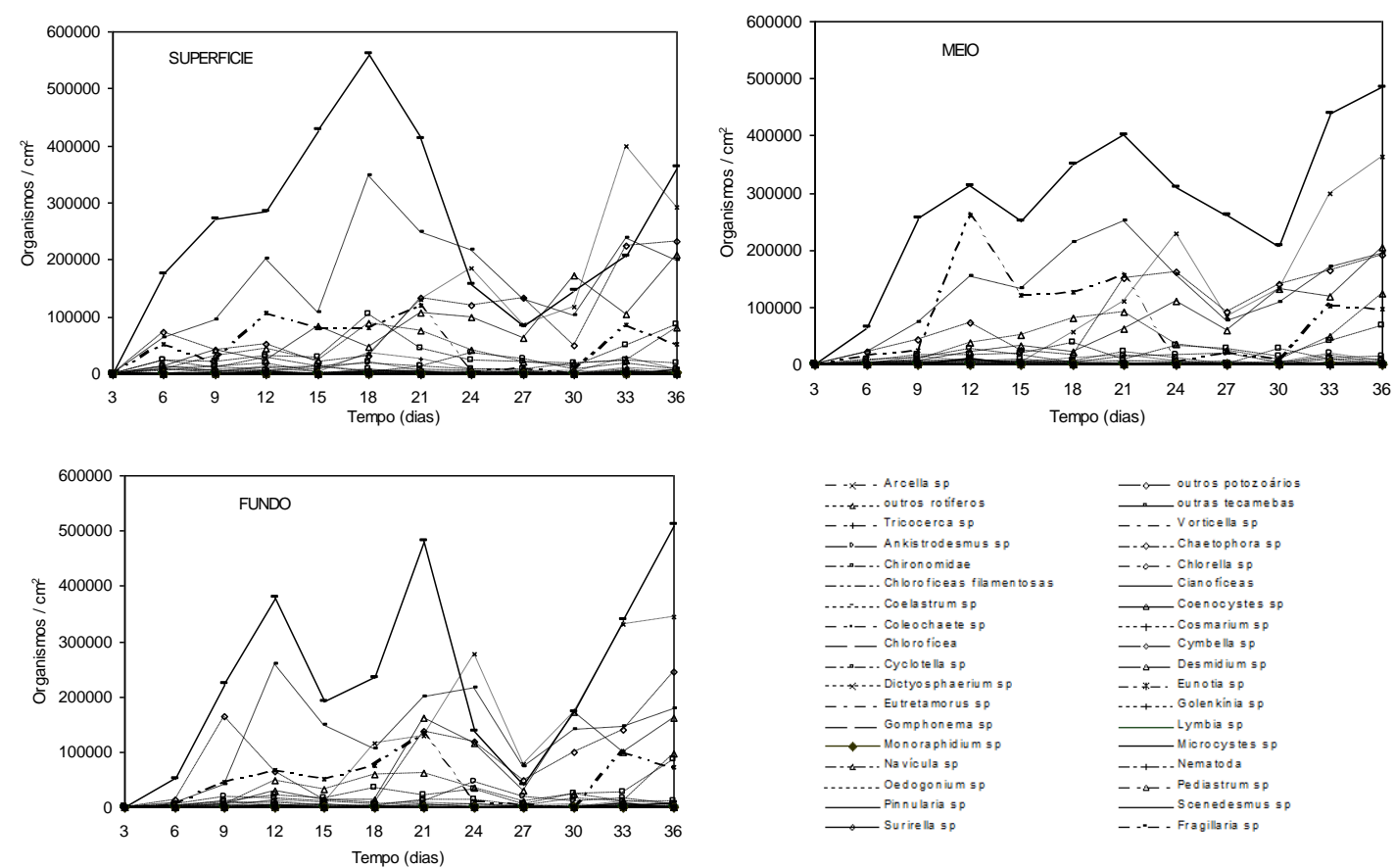

FIGURA 6- Densidade dos organismos perifíticos em diferentes níveis nos tanques adubados com esterco de suínos. 